\title{
Review Article \\ Sperm RNA as a Mediator of Genomic Plasticity
}

\author{
David Miller \\ Leeds Institute of Genetics and Health Therapeutics, University of Leeds, Clarendon Way, Leeds, West Yorkshire LS2 9JT, UK \\ Correspondence should be addressed to David Miller; d.miller@leeds.ac.uk
}

Received 2 July 2014; Revised 8 September 2014; Accepted 9 September 2014; Published 14 October 2014

Academic Editor: Angelo Veronese

Copyright (c) 2014 David Miller. This is an open access article distributed under the Creative Commons Attribution License, which permits unrestricted use, distribution, and reproduction in any medium, provided the original work is properly cited.

\begin{abstract}
Sperm RNA has been linked recently to trans-generational, non-Mendelian patterns of inheritance. Originally dismissed as "residual" to spermatogenesis, some sperm RNA may have postfertilization functions including the transmission of acquired characteristics. Sperm RNA may help explain how trans-generational effects are transmitted and it may also have implications for assisted reproductive technologies (ART) where sperm are subjected to considerable, ex vivo manual handling. The presence of sperm RNA was originally a controversial topic because nuclear gene expression is switched off in the mature mammalian spermatozoon. With the recent application of next generation sequencing (NGS), an unexpectedly rich and complex repertoire of RNAs has been revealed in the sperm of several species that makes its residual presence counterintuitive. What follows is a personal survey of the science behind our understanding of sperm RNA and its functional significance based on experimental observations from my laboratory as well as many others who have contributed to the field over the years and are continuing to contribute today. The narrative begins with a historical perspective and ends with some educated speculation on where research into sperm RNA is likely to lead us in the next 10 years or so.
\end{abstract}

\section{Introduction}

The recent publication of two reports on transgenerationally acquired inheritance (henceforth called TAC) in the mouse has brought the subject of sperm RNA back sharply into focus. The first of these [1] examined the transmission of a conditioned aversion to a particular odor in the F0s, which carried through to conditioned (and odor)-naïve F1 and F2 pups. The second report [2] demonstrated the inheritance of cognitive and behavioural conditioning in the F0s by F1 and $\mathrm{F} 2$ pups that had no prior experience of the conditioning (Figure 1). Although only the latter report went on to demonstrate a change in the (small noncoding) sperm RNA profile of conditioned mice that could be linked to the conditioning response and transmission, these reports, in association with earlier reports showing the transmission of paramutation effects by sperm RNA [3], strongly suggest that the odor conditioning was also transmitted by or associated with sperm RNA (or possibly sperm RNA-altered DNA methylation). In hindsight, the connection between sperm RNA and TAC now seems more obvious given that the transmission must go through the germ line [4]. Whether the RNA somehow marks the sperm genome before its entry into the ooplasm at fertilisation or is required to make its mark at some point after fertilisation remains unresolved to date. Moreover, it is unclear if the epigenetic information is carried by all or just sex-selected sperm otherwise the observed effects would be restricted to $[4,5]$ or independent of [3] gender. These recent reports shed light on earlier, human and animal-based studies, where some trauma or life "experience" in one generation is passed on to subsequent generations through the germ line. In human populations, the phenomenon is perhaps best known in relation to dietary or lifestyle habits with the Swedish Överkalix population being among the best studied [4]. In this population, dietaryassociated TAC effects appeared to skip a generation with paternal grandfathers' exposure during their slow growing period (SGP) in childhood affecting the mortality risk ratios of their grandsons but not granddaughters. Similar effects were seen linking paternal grandmothers with their granddaughters' mortality risk ratios although in this case dietary effects could also be linked back to the paternal grandmothers' time in utero or in early infancy. Direct father to offspring effects linking paternal smoking in the SGB with their sons' body mass index at 9 years of age have, however, been 


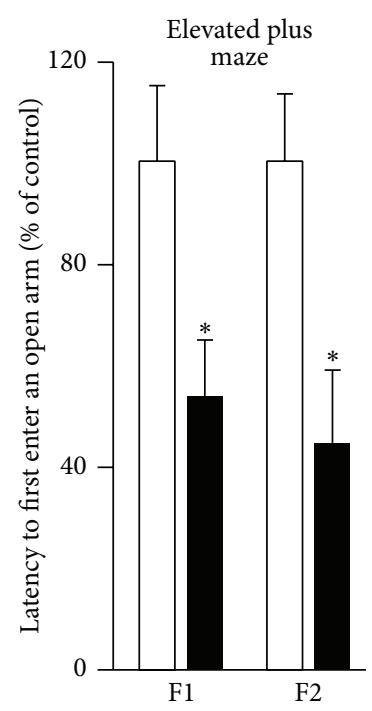

(a)

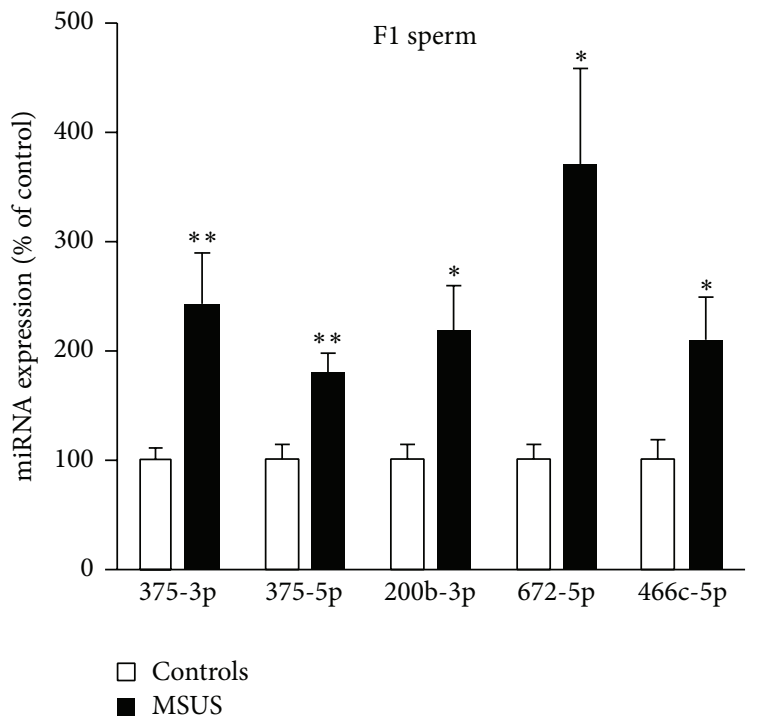

(d)

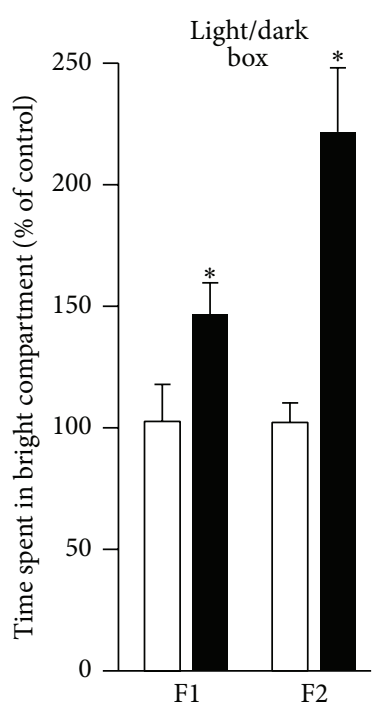

(b)

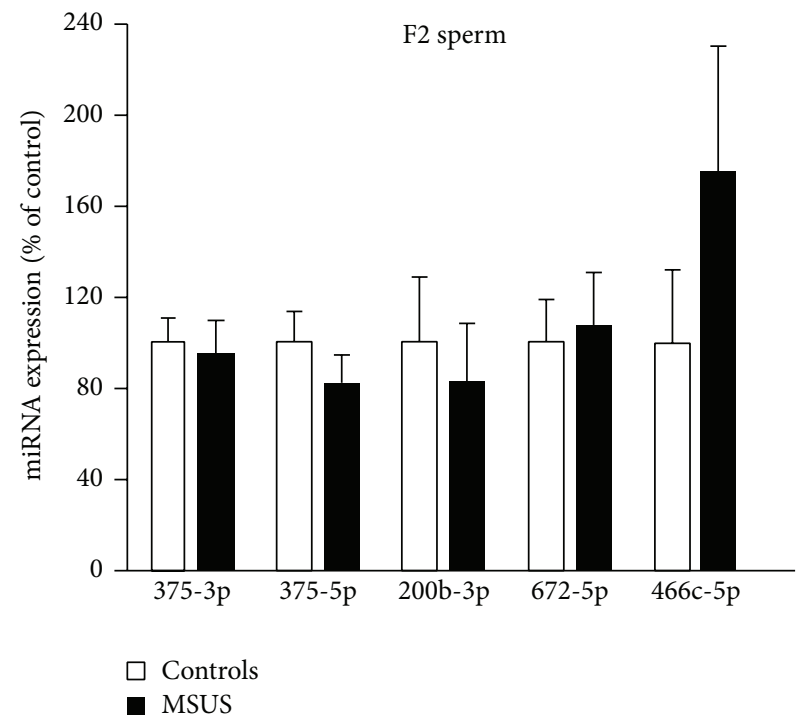

(e)

FIGURE 1: Sperm RNAs may be involved in transgenerational inheritance of the effects of early trauma in mice. Behavioral changes in male F1 and F2 mice from litters subjected to separation trauma based on maternal separation combined with unpredictable maternal stress (MSUS) were assessed. Compared with undisturbed control litters (white columns), MSUS males (black columns) entered an arm of an elevated maze more quickly (a), spent longer periods in the lit compartment of a light/dark box (b), and spent longer periods swimming in forced swim tests (c). These phenomena seem to be related to higher levels of certain metabolically relevant miRNAs in the sperm (and serum; not shown) from F1 MSUS males compared with F1 controls (a). Although F2 males do not show the same patterns of elevated miRNAs (b), they show very similar behaviours. With the exception of the forced swim tests, these behavioural effects were less marked among female progeny, adapted from Gapp et al. 2014, with permission.

observed in the Avon Longitudinal Study of Parents and Children (ALSPAC) [5].

We shall return to these matters in a later section (Section 5. The Future), but they are becoming all the more interesting because the spermatozoon of most higher animals (and plants) is a terminally differentiated and highly specialised cell, which until fairly recently was thought only to be a vessel for delivering the paternal genome safely to the oocyte. For that, it is exquisitely designed, being essentially a powerful flagellum at one end with a nucleus containing highly condensed chromatin at the other. Very little cytoplasm survives the elongation process and the linear relationship between head (nucleus), midpiece (mitochondria), and tail (flagellum) is optimised for an extended and potentially hazardous voyage across the female tract. Within the sperm nucleus (of eutherian mammals), DNA compaction is some 20 times greater than it is in round spermatids due to the general replacement of histones by arginine-rich protamines 


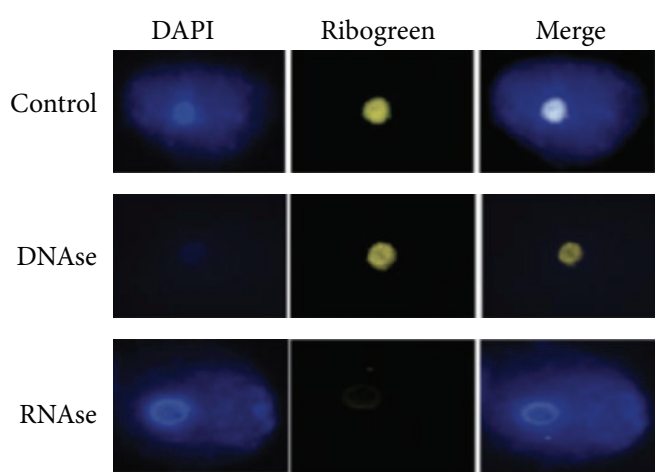

(a)

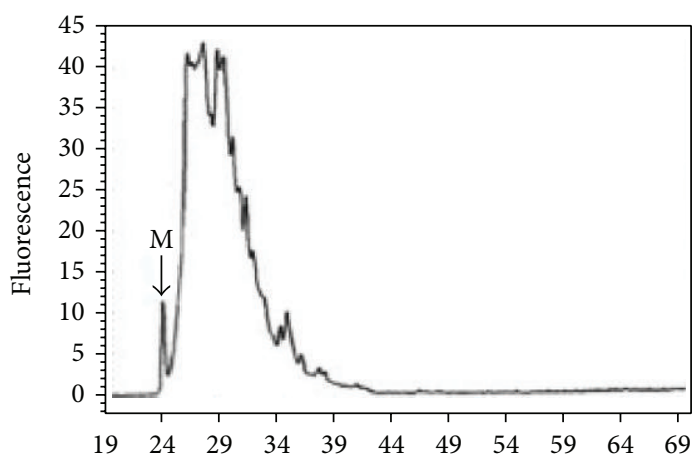

(c)

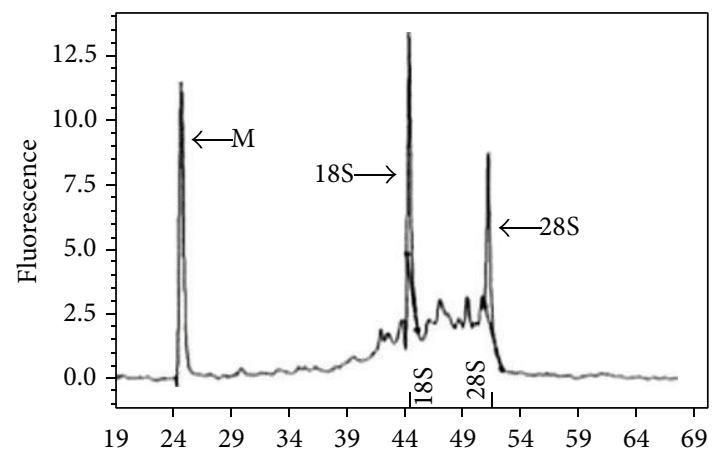

(b)

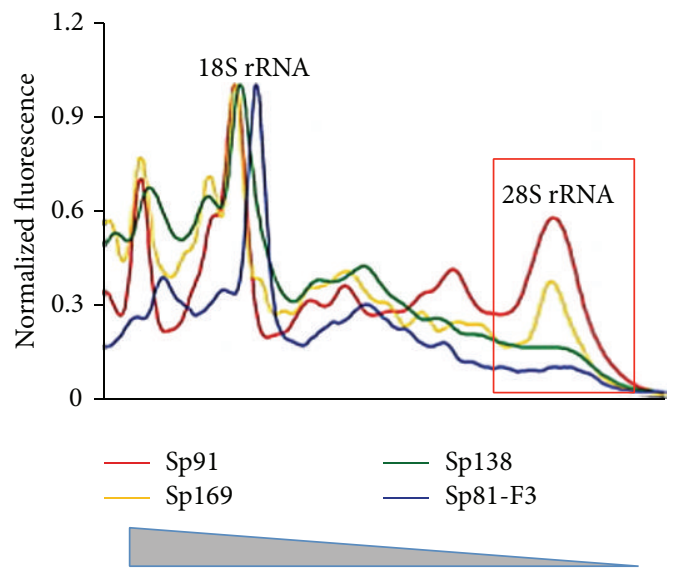

(d)

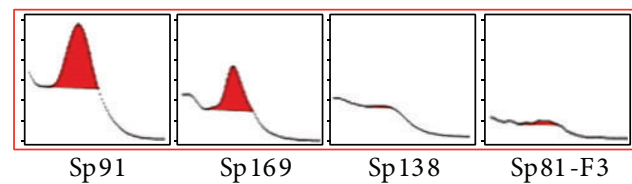

(e)

FIGURE 2: RNA in sperm. Sperm RNA is associated with the nuclear scaffold visualised here in a decondensed human spermatozoon nucleus (a) stained with RiboGreen. Compared with typical spermatids (b), where $28 \mathrm{~S}$ and $18 \mathrm{~S}$ rRNA dominate the cytoplasmic RNA profile, seen here on a Bioanalyzer trace (Agilent Technologies), sperm appear to be dominated by smaller RNAs which are essentially free of intact $28 \mathrm{~S}$ and 18S rRNA (c). The absence of these large subunit rRNAs has been used as a benchmark for purification of sperm to homogeneity. However one report suggests that although 28S RNA may indeed be depleted in sperm, ribosomes are present and the 18S RNA subunit can be detected if the background level of DNA contamination is reduced (d). The influence of round cell contamination in sperm preparations is shown in (e) for the individual sample $28 \mathrm{~S}$ rRNA peaks shown in (d); boxed. As the level of round cell contamination drops (wedge), the quantity of 28S RNA as indicated by the peak shading in (e) falls correspondingly, adapted with permission from Lalancette et al, 2008 (a); Gilbert et al, 2007 (b) and (c); and Cappallo-Obermann et al, 2011 (d) and (e). M indicates Marker.

$[6,7]$. This repackaging phenomenon confers an almost crystalline molecular structure to the chromatin of mature (mammalian) sperm nuclei and other animals making use of such substitutions (including fruit flies; [8]). Protamines probably arose independently from original histone-like proteins, several times in the evolutionary past by frame shift mutations because they enable the haploid paternal genome to be packaged into the smallest volume possible, perhaps conferring an advantage that is selected for [9]. Sperm RNA is embedded in or at least closely associated with the chromatin as various studies have demonstrated its nuclear localisation, Figure 2(a) [10-12]. The RNA may also perform a structural role within the sperm nuclear matrix, as it is known to associate with the nuclear lamina in somatic cells and its loss by RNAse leads to a general structural destabilisation of the nucleus $[13,14]$. Sperm RNA has been described and catalogued in the sperm of many species including animals and plants (reviewed most recently in [15-18]), highlighting not only the widespread nature of the phenomenon, but also its anomalous presence in what is traditionally viewed as a cell so highly specialised, that gene expression is completely shut down [19]. The presence of RNA in mature sperm is not that surprising if viewed as a relic of earlier, more active stages in spermatogenesis. Why should such an efficiently crafted 
cell bother wasting energy recycling RNA that has served its purpose and where no further transcription is required? Its presence could simply reflect the ending of a series of events required to facilitate the substitution of histones first, by transition proteins and then by protamines, where gene expression (transcription followed much later by translation) is progressively turned off during the postmeiotic stages of spe rmatogenesis, generally referred to as spermiogenesis [20]. Elongating spermatids in mammals and flies rely on translational control of stored mRNAs to complete the differentiation of the mature spermatozoon [21-25]. This temporal disconnect between transcription and translation accommodates the hypothesis that sperm RNA is residual to spermatogenesis and that its presence in the nucleus is due to it being trapped there during nuclear condensation. Very similar dynamics have been described in the sperm of the fruit fly, showing that the same solution to delivering the paternal genome to fly eggs has also arisen independently in a completely separate phylum [8]. Drosophila sperm also retains a complex repertoire of RNAs, underscoring the likely universality of "residual" RNA carriage by mature sperm [26].

More recent RNA-seq data supports the suggestion that the large spermatozoal (28S and 18S) rRNAs are degraded by fragmentation (probably by an unidentified nuclease), perhaps to close down and prevent further translation during spermatozoal maturation [27-29]. Indeed the presence of both truncated and full-length mRNAs in sperm in relation to their relative abundance suggests that an active digestion process is involved. Upregulation of endogenous endonuclease activity in sperm has been reported elsewhere [30, 31]; hence, an active RNAse activity during sperm maturation is likely. Nevertheless, the presence of small noncoding RNAs in the sperm of many species targeting a variety of gene sequences unrelated to spermatogenesis suggests that sperm RNA is more than just a residual relic of spermatogenesis $[2,16,18$, $29,32-46]$. Several reports, the most recent of which focused on sperm capacitation, have provided evidence that sperm RNA can be translated de novo [47, 48]. Capacitation is the term used to describe the events that take place following ejaculation that enables the spermatozoon to undergo an eggpenetrating acrosome reaction $[49,50]$. These newly synthesised proteins may serve to replace older proteins that are degraded or lost during capacitation. However, translation in sperm seems to be restricted to a mitochondrial pathway as it is sensitive to chloramphenicol but not cycloheximide. An earlier review correctly pointed out that in common with all other cells of the body, the mitochondrial ribosomal machinery in sperm should solely be responsible for synthesizing the 21 components of the respiratory transport chain encoded by the mitochondrial genome [51]. In this regard, although a relationship between extra-mitochondrial mitochondrial ribosomes and germ cell formation has been reported in insects and fish [52], how such a mechanism can support the translation of cytoplasmic RNAs (including nuclear-encoded RNAs for mitochondrial proteins) demands explanation. In a cautionary context, other reports have suggested that the reported translational activity in ejaculate sperm (even mitochondrially driven) could also be an artifact of bacterial contamination $[53,54]$. The more recent of these reports, however, while implicating bacteria fell short of actually demonstrating their presence in semen samples concerned.

\section{Historical Context}

This laboratory's earliest foray into sperm RNA was in its assessment as a convenient and sensitive marker of successful (or unsuccessful) human vasectomy [55]. We also reasoned that if ejaculate spermatozoa could provide equivalent information on what underlies a nonobstructive subfertile or infertile phenotype, a noninvasively obtained semen sample was surely a preferable and more widely acceptable option to testis biopsy. Our first report used a mix of RT-PCR targeting sperm-specific and nonspecific RNAs and the then relatively new "random" technique known as differential display (DD) PCR. The targeted approach detected protamine 2 (PRM2) and in the process showed that the RNA was processed (introns removed). Differential display hinted at many more RNA species and random cloning and sequencing of RNA display products revealed some of them, including an abundance of transcribed ALU-like sequences [56]. Shortly thereafter, an independent and now occasionally collaborating laboratory localised sperm RNA (including PRM2) to the nucleus by in situ hybridisation [57] and Figure 2(a), confirming earlier reports examining the location of small nuclear RNAs in human rodent and plant sperm $[10,11,58]$.

Although the functionality of spermatozoa is of considerable concern for clinicians investigating human male infertility and in animal husbandry, where semen quality is an essential economic consideration $[59,60]$, spermatology in general has tended to ignore gene expression in mature spermatozoa. Much of the earliest research in this area focused on bovine spermatozoa that were shown either capable $[61,62]$ or incapable $[53,63,64]$ of making RNA or protein. These early experiments [65] used methods that were relatively insensitive and potentially prone to the effects of bacterial contamination and growth. Precise studies on sperm gene expression began appearing only after the advent of more advanced radiochemical techniques. Between them, MacLaughlin and Terner [66] and Premkumar and Bhargava [67] demonstrated that mature bovine spermatozoa have no nuclear transcription to speak of (as might be expected) but that mitochondrial RNA was actively transcribed. Translation of (mitochondrial) RNAs was inferred rather than demonstrated at the time although at least one more recent report suggested that even mitochondrial gene expression is also absent in mature sperm [54].

The consensus that has arisen among molecular andrologists in recent years is that large cytoplamic (28S and $18 \mathrm{~S}$ ) ribosomal RNAs are either absent in sperm or are so heavily fragmented that they cannot support translation, despite earlier reports [68] of their presence, now presumed to be due to somatic cell contaminants. Using Bioanalyzer traces, our laboratory and others detected only smaller (shorter) RNAs in mature mammalian sperm $[56,69,70]$, Figures 2(b) and 2(c), with limited or no detection of large rRNAs although one recent report suggested that RNA extraction processes could be at least partly responsible for a failure to detect the smaller 
18S rRNA in human sperm [71], Figures 2(d) and 2(e). Nevertheless, a general rule of thumb for the isolation of pure populations of sperm RNA for downstream analyses (where even small amounts of contaminating somatic cell RNAs could be problematic) is that if the sperm RNA profile is essentially free of $28 \mathrm{~S}$ and $18 \mathrm{~S} \mathrm{rRNA}$, it is also free of nonsperm cell contaminants. The corollary of this assumption is that detection of the large rRNA subunits indicates a potential nonsperm cell contamination [71]. The question, therefore, of whether sperm has a translational capacity that cannot be ascribed to another contaminating cell type (including contaminating bacteria) remains open. De novo, chloramphenicol- (CP-) sensitive, mitochondrially directed protein synthesis in capacitating human sperm was recently demonstrated using the uptake of ${ }^{35} \mathrm{~S}$-methionine-lysine and BODIPY lysine tRNA [47] This report did not cite a study appearing three years earlier, concluding that protein synthesis in sperm was due to CP-sensitive bacterial contamination (repeating an assertion made almost 40 years previously; $[53,54])$. The only other report of de novo protein synthesis in sperm used a 2D PAGE based proteomic approach to identify 44 differentially expressed proteins in capacitated versus noncapacitated sperm including sperm capacitated in the presence of chloramphenicol [47]. These results were suggestive of a CP-sensitive, capacitation-dependent translational capacity; however, this technique did not involve any incorporation of a detectable marker that would aid the discrimination of newly translated protein (e.g., by stable isotope incorporation), a requirement to improve confidence in the results. Hence, the limited evidence suggesting that some sperm RNA can be translated de novo, perhaps as a replacement for proteins lost or degraded during capacitation or swimming remains inconclusive. While intriguing, a "hybrid" translational mechanism dependent on polysome complexes of mitochondrial origin would certainly require investigation in its own right. In conclusion, although the phenomenon of sperm RNA is now widely accepted and is not simply a reflection of contaminating somatic cells or residual cytoplasmic droplets $[72,73]$, defining its role remains a key goal of contemporary research efforts as considered below.

\section{Sperm RNA Revisited}

Assessing the complexity of any RNA population has only been possible with the advent of nontargeted PCR based approaches, first with differential display (DD), then with serial analysis of gene expression (SAGE) followed by the development of arrays and, ultimately, the wider availability of next generation sequencing (NGS). Each of these has been applied to sperm RNA and is worth considering in more detail. Together, they are leading us to conclude that sperm contain examples of just about every known RNA subtype in either an intact or fragmented form. One of our earliest reports [55] used DD to demonstrate the complexity of sperm RNA relative to RNA isolated from the endometrium and subsequently went on to identify some of these randomly primed cDNAs by simple excision of bands on agarose gels followed by conventional Sanger sequencing [56]. The collaborative ventures with Steve Krawetz in Detroit that followed [57] went on exploiting array technologies that pushed the numbers of (human) sperm mRNA species up to over 3,000 (see Miller and Ostermier, [18] for an earlier review). Similar studies have been undertaken on bull sperm where evidence for differential "expression" of some mRNAs in relation to bull fertility and return rates has been presented [69, 74-77]. Until very recently, sperm RNA composition of other animals had not been studied in such detail, mainly because microarray platforms for these species were unavailable. In this regard, a recent paper reported a similarly complex repertoire of RNAs isolated from the sperm of the fruit fly [26], extending the phenomenon to arthropods. Zhao et al. [78] commented on the abundance of RNAs derived from ribosomal protein complexes in fly sperm and a similar abundance reported in human sperm using SAGE. As many of these complexes are not represented on the array platforms used by human studies, they have not appeared in lists of sperm RNA transcripts derived from most array-based studies. The advantage of SAGE (like all DNA sequencing based strategies) is that it is not limited by the presence of specific probes on array platforms and so should provide more accurate descriptions of the relative abundance of mRNAs. The wider adoption of massively parallel RNA-seq in conjunction with better annotated genomes from domestic species has led to recent reports on the complexity of bovine [74], porcine [79], equine $[80]$, and murine $[2,32]$ sperm RNA. At the time of writing, the most comprehensive description of sperm RNA is from the human. Using a number of different methods for building sperm RNA-seq libraries for NGS, Sendler et al. [29] reported over 22,000 distinct RNA species in human sperm, eight times that reported by the same group previously using relatively primitive macroarrays $[29,81]$. Alternative strategies for building libraries (while keeping the same (Illumina) sequencing platform) helped assess the effects of library construction on sperm RNA sequence composition. For example, some libraries were built from polyA+ enriched RNA, which normally comprises less than $10 \%$ of the total RNA in a cell. Others made use of total RNA, attempting to cover all RNAs (including all short and many long noncoding) that are not polyadenylated. The advantage of selecting for polyA+ RNA is that it focuses primarily on the protein coding genome and, by ignoring all other RNAs, greater sequencing depth can be achieved, allowing more comprehensive coding mRNA catalogues to be compiled. Higher depth sequencing of sncRNAs can be achieved by size fractionation of total RNA to remove longer RNAs including most mRNAs beforehand. Sperm RNA is unusual in that much of it (estimated at $>70 \%$ ) is derived from fragmented $28 \mathrm{~S}$ and $18 \mathrm{~S}$ RNAs, which will tend to dominate the reads of total RNA sequencing runs including size fractionated RNA (and so reduce the sequencing depth for regions of interest overall) unless attempts are made to reduce its representation. Unfortunately, methods aimed at achieving this (RiboZero, for example) rely largely on secondary structure to recognise and remove large subunit rRNAs and so their utility with degraded RNA sources (including sperm RNA) can be unpredictable. Sendler et al. [29] used a single primer isothermal 
amplification based process (SPIA) in library construction that "ignores" ribosomal RNA sequences and so reduces their representation in libraries. The main findings from this study included confirmation that sperm RNA is heavily fragmented (probably to prevent illegitimate translation), with the $3^{\prime}$ ends of mRNA being more heavily truncated relative to $5^{\prime}$ ends. Distinct ontological descriptions persist, however, among the most abundant transcripts. A similar finding has been reported on murine sperm that also included rare evidence for the postfertilisation translation of some sperm RNAs in mouse zygotes [32]. Human sperm appear to have many RNAs with alternative polyadenylation (APA) sites compared with corresponding testis RNAs and, $3^{\prime}$ truncation may be a normal consequence of APA and hence under active cellular control (rather than a passive consequence of RNA fragmentation). These characteristics, including (in human sperm) the presence of RNAs derived from introns in genes expressed highly in the testis but where no such (coding) transcript persists, may also be found in the sperm from other species if fresh interrogations of their respective RNA-seq databases are undertaken.

Interestingly, surveys of sncRNAs from the sperm of several species have also appeared in recent years of which the human has been the most extensively studied. Based on size fractionated total RNA ( $<200 \mathrm{bp})$, Krawetz et al. [36] showed that over $65 \%$ of noncoding RNA in human sperm was derived from repetitive DNA sequence (primarily long (LINE) and short (SINE), Interspersed Nuclear Elements), with piRNAs and miRNAs, between them comprising another 25\% and Long Tandem Repeat (LTR) RNAs comprising almost $10 \%$. To some extent, these results reflect our earlier description of ALU-like RNAs in human spermatozoa [82]. The other studies focused mainly on noncoding RNAs and in human reported the presence of other less clearly defined sncRNA classes including RNAs aligning to transcription start sites (TSS) and promoter sequences [36]. Interestingly, the reported targets for human miRNAs and piRNAs were mainly directed towards repetitive, histone bound, and TSS/promoter sequences. As these sncRNAs are known to be involved in either regulating (miRNAs) mRNA expression or ensuring that the expression of repetitive sequences such as the LINE and LTR retroposons is repressed (piRNAs), their simultaneous presence alongside their targets is puzzling. Perhaps it reflects a dynamic process during spermiogenesis aimed at counteracting the temporarily weakened repression of repetitive sequence expression that may be a consequence of the repackaging of the genome [83]. Alternatively, sperm miRNAs and piRNAs may perform some function in the early zygote, perhaps related to the known expression of LTRs in the early embryo [84] or to some other paternally derived regulatory activity (see below). Although the existence of full term parthenotes using just maternally derived gametes suggests that such paternally derived epigenetic contributions are not required for "normal" development [85], sperm entry to the egg can be viewed as an invasive process. While gynogenic parthenotes are derived from two ultimately compatible maternal sources, RNAs delivered by the sperm may help facilitate a process of checking (C), recognition (R), and consolidation $(\mathrm{C})$ that permits the essentially "foreign" paternal genome to be accepted $[16,86]$. Although speculative, these suggestions have some scientific rationale behind them that could shed light on forms of male infertility arising from a dysfunction in the CRC process. In this regard, one could expect such dysfunctions to manifest as either a failure of fertilisation or a failure of successful activation of the embryonic genome. In human IVF clinics, the proportion of eggs that are successfully fertilised (two pronuclei visible) is $\sim 70 \%$. By comparison, in one study on frozen/thawed human embryos, the proportion of zygotes, day 3 embryos, and day 5 embryos (blastocysts) that went on to implant was much lower ( 13\%) [87].

\section{Clinical Utility}

It is only with the advent and rapid development of more advanced investigative methods and assays that assessment of the clinical potential of sperm RNA has become possible. Certainly the target gene-specific investigative strategies of the earlier days of transcriptome analysis have essentially been replaced by PCR arrays and microarrays capable of simultaneously interrogating hundreds or thousands of RNA sequences in a sample. Next generation sequencing (NGS) now offers at least an order of magnitude greater resolution for transcriptome profiling than even the best arrays can achieve and at comparable cost. The clinical diagnostic potential of sperm RNA has always been an attractive proposition because sperm can be easily obtained and early reports had already linked it to testicular gene expression [81]. As a noninvasive proxy for the testis, therefore, sperm RNA (or ejaculate RNA) can be viewed as "windows" into the testis or to the wider male reproductive secretory organs. In the author's view, this latter potential of the ejaculate is being currently underexploited. Certainly, early reports indicated that sperm RNA could be a useful indicator for motility (the most significant indicator of a fertile phenotype). Using discontinuous density gradients and RT-PCR, Lambard et al. [88] reported a reduction in the mRNA for protamines, eNOS and nNOS, in populations of highly motile sperm $(90 \%$ layer), compared with poorly motile sperm ( $44 \%$ layer). In conjunction with reports indicating that sperm from infertile men can display an altered protamine 1/protamine 2 (protein) ratio (1:1 is the norm) indicative of aberrant DNA packaging $[89,90]$, reports of RNA "loss" in motile sperm could indicate an active translational replacement of degraded proteins accompanied by a subsequent turnover and loss of coding RNA. Quid pro quo, higher levels of the RNA in immotile or poorly motile sperm could indicate translational failure. The work described previously demonstrating a translation capacity in mature sperm supports this hypothesis [47].

More recently, clinical reports have begun to appear, comparing sperm mRNA profiles using either array-PCR covering a defined batch of selected gene probes or whole genome microarrays with many thousands of unselected gene probes. Using the Agilent whole genome microarray platform, García-Herrero et al. (2011) [91] were able to identify differences in the sperm RNA profiles between couples achieving or not achieving pregnancy by intrauterine insemination 


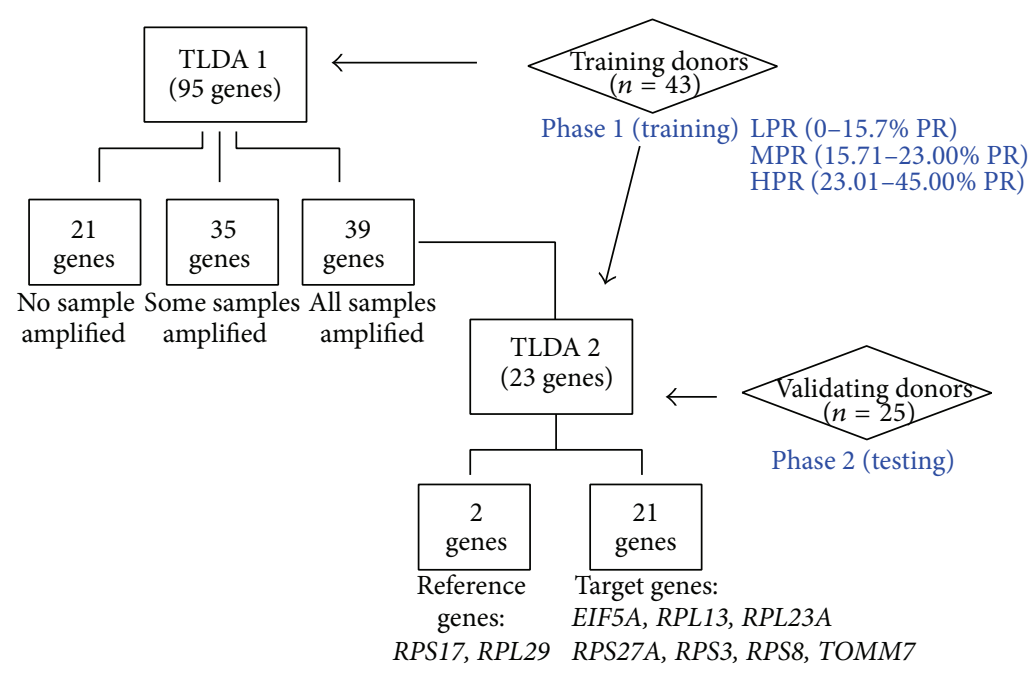

FIGURE 3: TaqMan low density array (TLDA) workflow for assessing sperm RNA expression profile in relation to (IUI) pregnancy rate. Flow chart representing the number of individuals and candidate genes going through the different work-procedure stages. TLDA: training donors in Phase 1 were classified into three groups (tertiles) according to the pregnancy rate (PR) obtained after IUI: low (0 to 15.70\% PR: Group (1); medium 15.71 to 23.00\% PR: Group (2); high (23.01 to 45.0\% PR: Group (3), adapted from Bonache et al, 2012.

(IUI). In an earlier report from the same group but using an array-PCR based approach, Garrido et al. [92] detected clear differences between the sperm RNA profiles of fertile and infertile men but with no discernible differences in their respective semen profiles as characterized by the WHO (1999) reference manual $[92,93]$. A similar study using a TaqMan array-PCR based approach reported reproducible differences in the sperm RNA levels from 87 target genes from normozoospermic donors [94]. This study examined 68 sperm samples, by far the largest sample size for any sperm RNA study published to date. It also derived some useful statistical outputs capable of distinguishing between donors with a high or low chance of achieving successful pregnancy by IUI (Figure 3). These studies suggest that molecular anomalies can give rise to forms of infertility that cannot always be detected or distinguished by a standard semen analysis. With regard to phenotypes, Platts et al. [95], using the Affymetrix U133 + 2 array platform, were easily able to cluster sperm RNA profiles into normozoospermic and teratozoospermic categories based on comparisons between 31 samples (17 normozoospermic and 14 teratozoospermic). This paper also reported a significant ontological signature for RNAs encoding proteins involved in the ubiquitin-proteasome regulated protein recycling pathways (downregulated in the teratozoospermic cohort). In this regard, comparative but far more detailed NGS studies using similar cohorts should be considered, where both coding and noncoding RNAs can be more comprehensively characterized and assessed.

Interestingly, although much of the emphasis on isolating pure populations of sperm RNA arose because of the initial skepticism surrounding its existence, there is no reason for such caution when considering its utility in a clinical setting as currently, the WHO manual for semen analysis recommends assessment for the presence of other cell types present in the ejaculate including leukocytes and other somatic cells.
Using unprocessed semen, for example, and a target-specific RT-PCR approach, Yatsenko et al. were able to identify suspected mutations in the germ cell specific KLHL10 gene causing an infertile phenotype [96]. Similar, nonselective approaches could be used for future NGS studies providing transcription profiles that are not restricted to spermatozoa alone. Such an approach could also permit the noninvasive molecular characterisation of other parts of the male reproductive axis including the prostate and seminal vesicles.

\section{The Future}

Apart from its promising future in a clinical diagnostic setting, one of the more intriguing research questions regarding sperm RNA is whether it has an extra-spermatozoal function. Being the only cell in the body specifically designed to gain entry into another (the oocyte), such a function may not be trivial and as such could have implications for assisted reproduction technologies in general and particularly for Intra-Cytoplasmic Sperm Injection (ICSI). The discovery of a paramutation effect for a cKit mediated phenotype on coat colour has added considerable weight to this possibility and suggests that the mechanism of transmission is nonMendelian and involves sperm RNA [3]. Paramutation is mutation that does not involve the DNA sequence per se as the effect is observed in the presence of animals displaying the mutated phenotype (in this case, white tail tips and paws) but carrying wild-type alleles. This study also reported that sperm from mice heterozygous for the mutant Kit allele carried unusually high levels of RNA (presumably, deregulated Kit transcripts) into the oocyte compared with homozygous wild-type animals. The same paramutated phenotype was observed in wild-type crosses after microinjection of the zygotes with either total RNA from heterozygous animals 
(presumed to be brain) or Kit-specific miRNAs. A largeoffspring effect using microinjection of a particular miRNA (miR-124) targeting the Sox 9 gene promoter was later reported [97] suggesting that the oocyte is sensitive to RNA ingress that can affect subsequent phenotypes (perhaps by inducing downstream zygotic DNA methylation events) and that the most likely source of this RNA is the fertilising sperm itself. In this regard, one particular miRNA (miR-34c), involved in p53 regulation, is thought to be important in promoting a postmeiotic phenotype driving spermiogenesis $[39,98]$. This miRNA is also present in relatively high abundance in both human [16] and mouse [34] sperm and in the latter, evidence for its involvement in embryonic genome activation by selective miR-34c knock-down in recipient oocytes has been presented [34] but contradicted by another, wholly unrelated study showing that mice carrying a deletion of all three miR-34 members are fully fertile [99].

TAC effects in animal models have focused mainly on fetal exposure to cytotoxic agents in the rat. Anway and Skinner were the first to report such an effect (impaired spermatogenesis) in up to the F4 generation in males derived from F0 females exposed to the fungicide vinclozolin [100]. In the absence of classical mutation, only epigenetic effects on phenotype beyond the F2 generation can be considered truly transgenerational because the F1s (male and female) would have been exposed to the systemic presence of the fungicide in the F0 uterus. The F2 primordial germ cells developing in the F1 embryos could be affected likewise. The two reports mentioned in the introduction to this review as well as others appearing in the last few months have essentially brought sperm back into focus as the likely vehicle for TAC and sperm RNA and/or stably inherited (RNA-mediated?) sperm DNA methylation as the likely carrier. Differences in the miRNA content of sperm from F1 and F2 maternal separation combined with unpredictable maternal stress (MSUS) conditioned versus nonconditioned control mice were noted in one study after injection of naive zygotes with sperm RNAs isolated from MSUS males [2] Figure 4. The other study using olfactory conditioning in the F0 generation detected heritable changes in the methylation of sperm DNA corresponding with the epigenetic transmission to FI and F2 offspring [1]. As siRNAs can induce gene expression downregulation by cytosine methylation on CpG sites [101] it is tempting to consider differential sperm RNA carriage and subsequent or possibly complementary changes in DNA methylation as having similar effects (Figure 4). Both of these cases can be considered truly transgenerational despite the lack of information from F3 or F4 generations because neither F1 nor F2 generations were exposed to conditioning regimens that can be regarded as systemic (unlike the earlier experiments with vinclozolin). In all of these cases, it appears that a somatic stress is being transferred to the germ line. Moreover, somatic traits targeted at male gametes would either have to cross the blood-testis barrier in order to reach their target or bypass it altogether. The latter option is possible in view of the potential carriage of RNAs by exosomes in the circulation and the transfer of exosomes to mature sperm while they are traversing the epididymis [102-104].
In this regard, another interesting development regarding potential TAC effects in the human is with testicular dysgenesis syndrome (TGS), a phenomenon associated with the observed rise in western human populations in the incidence of cryptorchidism, hypospadias, and testicular cancer [105]. Although it is very difficult to prove causation in humans, TGS is probably influenced by fetal exposure to endocrine disrupters such as phthalates [106]. A more accessible marker for such exposure during uterine life is anogenital distance (AGD), which is naturally shorter in females than in males. Exposure to endocrine disrupters during the so-called "masculisation programming window" in rat gestation leads to a shortening of the distance in males but not females [107]. Several studies in humans have now also confirmed a shortening in anogenital distance associated with a higher prevalence of cryptorchidism, hypospadias, and lower sperm counts. Alongside the evidence for the effects of high levels of maternal glucocorticoid exposure on offspring in both animals and humans (the original metabolic syndrome; [108]) with associated TAC effects, evidence for "windows of opportunity" during fetal development (and early childhood) where external, environmental influences can modulate phenotype, most likely through epigenetic mechanisms is becoming stronger. The demonstrations of germ line (particularly male, sperm)-mediated TAC, first put forward as a component of the notion of "soft inheritance" by Henri Lamark in 18th and early 19th centuries [109, 110] and subsequently revisited several times since has once again come to the fore. The theory that TAC is the means by which evolutionary change is driven was eventually supplanted by the now accepted dogmas of Darwinian based fixation of rare but beneficial mutations by natural selection and the Mendelian segregation of genetic information. TAC upsets widely accepted notions that any DNA methylation events induced in F0 gametes will not survive fertilisation and into the F1s [111] or if they do will be lost during subsequent differentiation of the primordial germ cells and so cannot persist into the F2s [112]. It also violates the Weissmann principle on germ line to soma transmission of genetic information but is an attractive proposition for adaptation because it operates at a much faster rate than is possible with conventional Mendelian based mechanisms of inheritance. TAC thereby offers a way for organisms to respond to rapidly changing environmental conditions or exposures and potentially boosting the chances of their offspring's survival by giving them an adaptive advantage. In the author's and others view [110], this is fully compatible with neo-Darwinian concepts of fitness and survival.

\section{A Dilemma for IVF?}

If epigenetic changes are at the heart of TAC with gametes (particularly sperm) as the main vectors, the implications for assisted reproduction are profound. Gametes for IVF are obtained from couples and in so doing are removed from their normal background environments. Superovulatory regimens, in particular, can expose follicles to oxidative and 


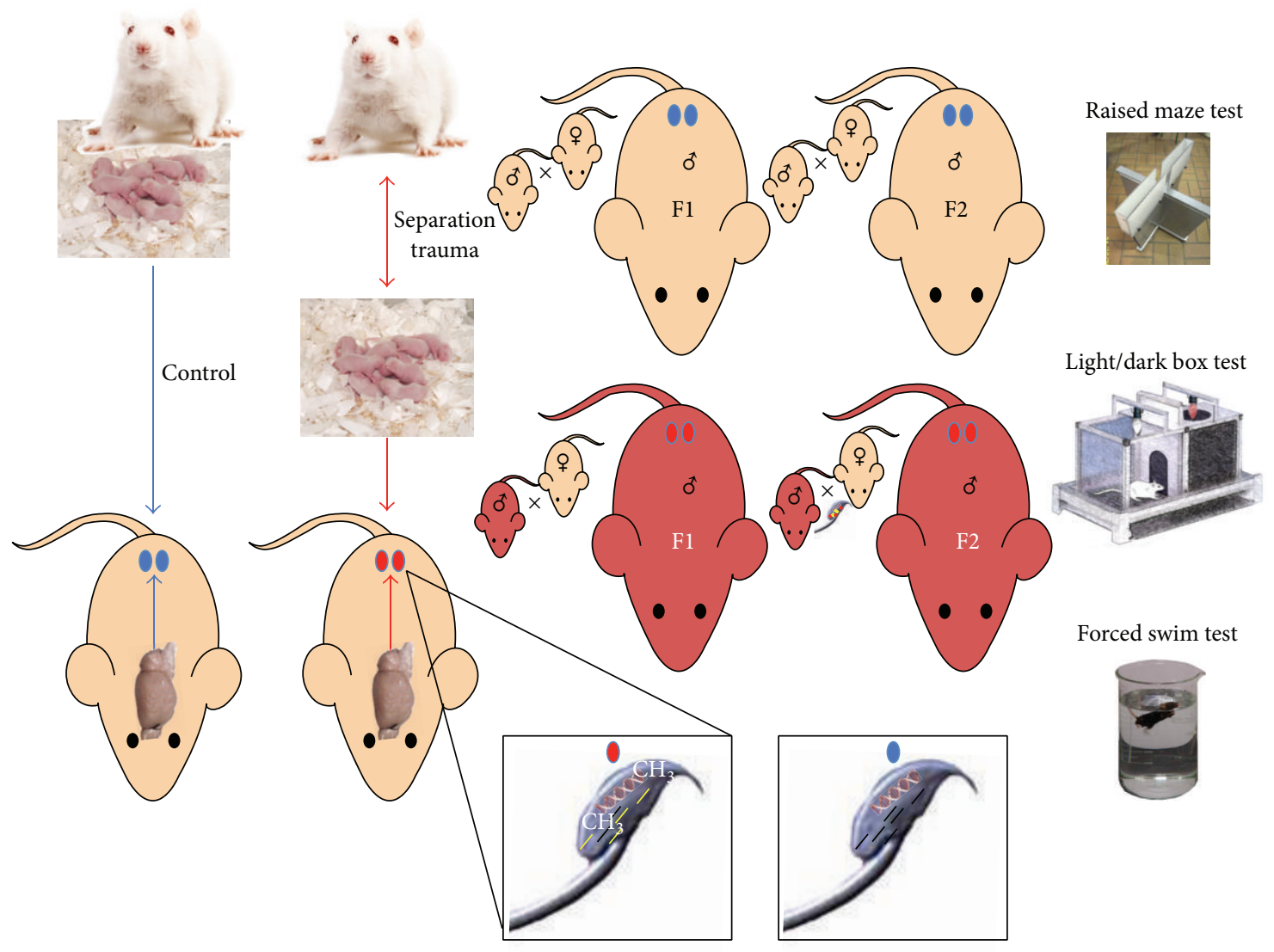

FIGURE 4: Schematic for sperm RNA-mediated transgenerational inheritance. Cartoon depicting possible modifications in sperm RNA content (yellow bars) over background (black bars) in relation to behavioral changes in male F1 and F2 mice from litters subjected to separation trauma based on maternal separation combined with unpredictable maternal stress (MSUS). Alterations in behaviour in response to the stressor must be neurological in origin and for transmission to the F1s derived from those males neurological changes must somehow be signaled to gametes. Evidence presented by Gapp et al. [120] suggests that the signal could be transmitted in the circulation to the male reproductive system by miRNAs or their precursors. One testable hypothesis is that the sperm-derived RNA signal may only be required for F0 (stress exposed) to F1 transgenerational transmission before becoming imprinted in the DNA epigenome ( $\mathrm{CH}_{3}$ groups in sperm cartoon) in the F1 zygote and hence transmitted by sperm DNA into the F2 and subsequent generations; this RNA-mediated effect could equally, however, involve demethylation. In this author's view, miRNAs may not be required to traverse the blood testis barrier if they first encounter mature sperm passing through the epididymis via exosomes, adapted from Gapp et al, 2014.

proinflammatory conditions that may put them at developmental risk. However, it could be argued that sperm are at potentially greater risk because of their extended processing. In most IVF labs, sperm are washed free of seminal plasma by density gradient centrifugation and are often incubated for prolonged periods at $37^{\circ} \mathrm{C}$. We know that sperm can potentially upregulate endogenous endonucleases capable of initiating digestion of their own DNA (and probably RNA) [30] and that this may be a time dependent phenomenon [113]. However, very little is known about how sperm processing can affect the cells' epigenetic status. One landmark study demonstrated a relationship between differential levels of sperm DNA methylation and IVF outcomes [114]; a later study reported correlations between sperm DNA methylation and semen quality, based on standard assessment criteria including concentration, morphology, and motility [115].
A third study demonstrated the accidental transgenesis of mouse embryos by bacterial DNA following ICSI [116]. Although beyond the scope of this review, other studies in various species have shown that sperm can carry exogenous nucleic acids into the egg and that this process can be used to produce transgenic animals (see [117] for a recent review and [118]). If as current research suggests the gametes are the vessels and either RNA carriage or DNA methylation is the vectors of transgenerational information, then being taken out of context (the body), gametes may open another "epigenetic programming window" that could inadvertently introduce subtle changes affecting the epigenetic signature. In the assisted conception field, whether these changes are for the good or ill (or even exist at all) will only be determined by long term follow-up observation of IVF children. In this regard, children conceived by ICSI need particularly careful 
attention because, in their case, the potentially filtering barriers of egg zona pellucida and egg membrane binding were bypassed altogether.

\section{Conclusions}

The story of sperm RNA has come a long way since its original description in the late 1950s and early 1960s. We now appreciate that it is present in all sperm types investigated so far, including mammalian, insect, and plant species. Sperm RNA represents an intrinsic "record" of past events in spermatogenesis but recent evidence now suggests that it has extrinsic roles beyond the spermatozoon itself. In the former context, sperm RNA will be useful resource for improvements in the diagnosis and management of male infertility. In the latter context, sperm RNA may be key to understanding the transmission of epigenetic characteristics to subsequent offspring and its connection with recently revisited forms of transgenerational inheritance. It is the author's professional view that TAC is likely to be the driver for future research into functional aspects of sperm RNA.

Since revising this paper, a paper has appeared demonstrating the soma (transplanted tumour cells) to germ line transmission of a synthetic marker RNA (EGFP) into F0 mouse sperm [119]. The EGFP RNA, expressed from an episomal plasmid in subcutaneously xenografted human tumour cells, was also detected in circulating exosomes (derived from the tumour cells) and in epididymal sperm. The current hypothesis explaining this result is that exosomes carrying the EGFP RNA escape from the tumour cells enter the circulation and subsequently merge with sperm cells during their transport across the epididymis. A similar transport mechanism may be operating in the transfer of RNAs from the brain or olfactory bulb of fear conditioned mice to their sperm $[1,120]$. It will be interesting to see if the EGFP marker can be transgenerationally acquired by F1 and F2 males.

\section{Conflict of Interests}

The author declares that there is no conflict of interests regarding the publication of this paper.

\section{References}

[1] B. G. Dias and K. J. Ressler, "Parental olfactory experience influences behavior and neural structure in subsequent generations," Nature Neuroscience, vol. 17, no. 1, pp. 89-96, 2014.

[2] K. Gapp, A. Jawaid, P. Sarkies et al., "Implication of sperm RNAs in transgenerational inheritance of the effects of early trauma in mice," Nature Neuroscience, vol. 17, no. 5, pp. 667-669, 2014.

[3] M. Rassoulzadegan, V. Grandjean, P. Gounon, S. Vincent, I. Gillot, and F. Cuzin, "RNA-mediated non-mendelian inheritance of an epigenetic change in the mouse," Nature, vol. 441, no. 7092, pp. 469-474, 2006.

[4] M. E. Pembrey, L. O. Bygren, G. Kaati et al., "Sex-specific, maleline transgenerational responses in humans," European Journal of Human Genetics, vol. 14, no. 2, pp. 159-166, 2006.

[5] K. Northstone, J. Golding, G. Davey Smith, L. L. Miller, and M. Pembrey, "Prepubertal start of father's smoking and increased body fat in his sons: further characterisation of paternal transgenerational responses," European Journal of Human Genetics, 2014.

[6] R. Balhorn, L. Brewer, and M. Corzett, "DNA condensation by protamine and arginine-rich peptides: analysis of toroid stability using single DNA molecules," Molecular Reproduction and Development, vol. 56, supplement 2, pp. 230-234, 2000.

[7] G. Fuentes-Mascorro, H. Serrano, and A. Rosado, "Sperm chromatin," Archives of Andrology, vol. 45, no. 3, pp. 215-225, 2000 .

[8] C. Rathe, W. M. Baarends, S. Jayaramaiah-Raja, M. Bartkuhn, R. Renkawitz, and R. Renkawitz-Pohl, "Transition from a nucleosome-based to a protamine-based chromatin configuration during spermiogenesis in Drosophila," Journal of Cell Science, vol. 120, part 9, pp. 1689-1700, 2007.

[9] R. Balhorn, "The protamine family of sperm nuclear proteins," Genome Biology, vol. 8, no. 9, article 227, 2007.

[10] E. Rejon, C. Bajon, A. Blaize, and D. Robert, "RNA in the nucleus of a motile plant spermatozoid: characterization by enzyme-gold cytochemistry and in situ hybridization," Molecular Reproduction and Development, vol. 1, no. 1, pp. 49-56, 1988.

[11] C. A. Pessot, M. Brito, J. Figueroa, I. I. Concha, A. Yanez, and L. O. Burzio, "Presence of RNA in the sperm nucleus," Biochemical and Biophysical Research Communications, vol. 158, no. 1, pp. 272-278, 1989.

[12] S. M. Wykes and S. A. Krawetz, "The structural organization of sperm chromatin," Journal of Biological Chemistry, vol. 278, no. 32, pp. 29471-29477, 2003.

[13] W. W. Franke, "Nuclear envelopes: structure and biochemistry of the nuclear envelope," Philosophical Transactions of the Royal Society of London Series B: Biological Sciences, vol. 268, no. 891, pp. 67-93, 1974.

[14] G. D. Johnson, C. Lalancette, A. K. Linnemann, F. Leduc, G. Boissonneault, and S. A. Krawetz, "The sperm nucleus: chromatin, RNA, and the nuclear matrix," Reproduction, vol. 141, no. 1, pp. 21-36, 2011.

[15] J.-P. Dadoune, "Spermatozoal RNAs: what about their functions?" Microscopy Research and Technique, vol. 72, no. 8, pp. 536-551, 2009.

[16] M. Jodar, S. Selvaraju, E. Sendler, M. P. Diamond, and S. A. Krawetz, "The presence, role and clinical use of spermatozoal RNAs," Human Reproduction Update, vol. 19, no. 6, pp. 604-624, 2013.

[17] C. Lalancette, D. Miller, Y. Li, and S. A. Krawetz, "Paternal contributions: new functional insights for spermatozoal RNA," Journal of Cellular Biochemistry, vol. 104, no. 5, pp. 1570-1579, 2008.

[18] D. Miller and G. C. Ostermeier, "Towards a better understanding of RNA carriage by ejaculate spermatozoa," Human Reproduction Update, vol. 12, no. 6, pp. 757-767, 2006.

[19] N. B. Hecht, "Molecular mechanisms of male germ cell differentiation," BioEssays, vol. 20, no. 7, pp. 555-561, 1998.

[20] R. Balhorn, M. Cosman, K. Thornton et al., "Protamine mediated condensation of DNA in mammalian sperm," in The Male Gamete: From Basic Science to Clinical Applications, C. Gagnon, Ed., pp. 55-70, River Press, 1999.

[21] R. E. Braun, J. J. Peschon, R. R. Behringer, R. L. Brinster, and R. D. Palmiter, "Protamine $3^{\prime}$-untranslated sequences regulate temporal translational control and subcellular localization of growth hormone in spermatids of transgenic mice," Genes \& Development, vol. 3, no. 6, pp. 793-802, 1989. 
[22] T. A. Brevini-Gandolfi, L. A. Favetta, L. Mauri, A. M. Luciano, F. Cillo, and F. Gandolfi, "Changes in poly(A) tail length of maternal transcripts during in vitro maturation of bovine oocytes and their relation with developmental competence," Molecular Reproduction and Development, vol. 52, no. 4, pp. 427-433, 1999.

[23] B. Gold, H. Fujimoto, J. M. Kramer, R. P. Erickson, and N. B. Hecht, "Haploid accumulation and translational control of phosphoglycerate kinase-2 messenger RNA during mouse spermatogenesis," Developmental Biology, vol. 98, no. 2, pp. 392-399, 1983.

[24] W. Gu and Y. K. Kwon, "In postmeiotic male germ cells poly (A) shortening accompanies translation of mRNA encoding gamma enteric actin but not cytoplasmic beta and gamma actin mRNAs," Molecular Reproduction and Development, vol. 44, no. 2, pp. 141-145, 1996.

[25] H. White-Cooper and I. Davidson, "Unique aspects of transcription regulation in male germ cells," Cold Spring Harbor Perspectives in Biology, vol. 3, no. 7, 2011.

[26] B. E. Fischer, E. Wasbrough, L. A. Meadows et al., "Conserved properties of Drosophila and human spermatozoal mRNA repertoires," Proceedings of the Royal Society B: Biological Sciences, vol. 279, no. 1738, pp. 2636-2644, 2012.

[27] E. Sendler, G. D. Johnson, and S. A. Krawetz, "Local and global factors affecting RNA sequencing analysis," Analytical Biochemistry, vol. 419, no. 2, pp. 317-322, 2011.

[28] G. D. Johnson, E. Sendler, C. Lalancette, R. Hauser, M. P. Diamond, and S. A. Krawetz, "Cleavage of rRNA ensures translational cessation in sperm at fertilization," Molecular Human Reproduction, vol. 17, no. 12, pp. 721-726, 2011.

[29] E. Sendler, G. D. Johnson, S. Mao et al., "Stability, delivery and functions of human sperm RNAs at fertilization," Nucleic Acids Research, vol. 41, no. 7, pp. 4104-4117, 2013.

[30] B. Sotolongo, T. T. F. Huang, E. Isenberger, and W. S. Ward, "An endogenous nuclease in hamster, mouse, and human spermatozoa cleaves DNA into loop-sized fragments," Journal of Andrology, vol. 26, no. 2, pp. 272-280, 2005.

[31] B. Sotolongo, E. Lino, and W. S. Ward, "Ability of hamster spermatozoa to digest their own DNA," Biology of Reproduction, vol. 69, no. 6, pp. 2029-2035, 2003.

[32] P. Fang, P. Zeng, Z. Wang et al., "Estimated diversity of messenger RNAs in each murine spermatozoa and their potential function during early zygotic development," Biology of Reproduction, vol. 90, no. 5, article 94, 2014.

[33] J. Kiani and M. Rassoulzadegan, "A load of small RNAs in the sperm-how many bits of hereditary information?" Cell Research, vol. 23, no. 1, pp. 18-19, 2013.

[34] W.-M. Liu, R. T. K. Pang, P. C. N. Chiu et al., "Sperm-borne microRNA-34c is required for the first cleavage division in mouse," Proceedings of the National Academy of Sciences of the United States of America, vol. 109, no. 2, pp. 490-494, 2012.

[35] A. Govindaraju, A. Uzun, L. Robertson et al., "Dynamics of microRNAs in bull spermatozoa," Reproductive Biology and Endocrinology, vol. 10, article 82, 2012.

[36] S. A. Krawetz, A. Kruger, C. Lalancette et al., "A survey of small RNAs in human sperm," Human Reproduction, vol. 26, no. 12, pp. 3401-3412, 2011.

[37] P. C. Au, S. Frankenberg, L. Selwood, and M. Familari, "A novel marsupial pri-miRNA transcript has a putative role in gamete maintenance and defines a vertebrate miRNA cluster paralogous to the miR-15a/miR-16-1 cluster," Reproduction, vol. 142, no. 4, pp. 539-550, 2011.
[38] G. Le Trionnaire and D. Twell, "Small RNAs in angiosperm gametophytes: from epigenetics to gamete development," Genes and Development, vol. 24, no. 11, pp. 1081-1085, 2010.

[39] F. Bouhallier, N. Allioli, F. Lavial et al., "Role of miR-34c microRNA in the late steps of spermatogenesis," RNA, vol. 16, no. 4, pp. 720-731, 2010.

[40] Z. He, M. Kokkinaki, D. Pant, G. I. Gallicano, and M. Dym, "Small RNA molecules in the regulation of spermatogenesis," Reproduction, vol. 137, no. 6, pp. 901-911, 2009.

[41] R. Grant-Downton, G. le Trionnaire, R. Schmid et al., "MicroRNA and tasiRNA diversity in mature pollen of Arabidopsis thaliana," BMC Genomics, vol. 10, article no. 643, 2009.

[42] R. Grant-Downton, S. Hafidh, D. Twell, and H. G. Dickinson, "Small RNA pathways are present and functional in the angiosperm male gametophyte," Molecular Plant, vol. 2, no. 3, pp. 500-512, 2009.

[43] C. Chambers and B. Shuai, "Profiling microRNA expression in Arabidopsis pollen using microRNA array and real-time PCR," BMC Plant Biology, vol. 9, article 87, 2009.

[44] E. Marcon, T. Babak, G. Chua, T. Hughes, and P. B. Moens, "miRNA and piRNA localization in the male mammalian meiotic nucleus," Chromosome Research, vol. 16, no. 2, pp. $243-$ 260, 2008 .

[45] S. T. Grivna, E. Beyret, Z. Wang, and H. Lin, "A novel class of small RNAs in mouse spermatogenic cells," Genes and Development, vol. 20, no. 13, pp. 1709-1714, 2006.

[46] G. C. Ostermeier, R. J. Goodrich, J. S. Moldenhauer, M. P. Diamond, and S. A. Krawetz, "A suite of novel human spermatozoal RNAs," Journal of Andrology, vol. 26, no. 1, pp. 70-74, 2005.

[47] Y. Gur and H. Breitbart, "Mammalian sperm translate nuclearencoded proteins by mitochondrial-type ribosomes," Genes \& Development, vol. 20, no. 4, pp. 411-416, 2006.

[48] C. Zhao, X.-J. Guo, Z.-H. Shi et al., "Role of translation by mitochondrial-type ribosomes during sperm capacitation: an analysis based on a proteomic approach," Proteomics, vol. 9, no. 5, pp. 1385-1399, 2009.

[49] D. Ickowicz, M. Finkelstein, and H. Breitbart, "Mechanism of sperm capacitation and the acrosome reaction: role of protein kinases," Asian Journal of Andrology, vol. 14, no. 6, pp. 816-821, 2012.

[50] P. E. Visconti, D. Krapf, J. L. de la Vega-Beltrán, J. J. Acevedo, and A. Darszon, "Ion channels, phosphorylation and mammalian sperm capacitation," Asian Journal of Andrology, vol. 13, no. 3, pp. 395-405, 2011.

[51] M. A. Baker, "The 'omics revolution and our understanding of sperm cell biology," Asian Journal of Andrology, vol. 13, no. 1, pp. 6-10, 2011.

[52] R. R. Zhou, B. Wang, J. Wang, H. Schatten, and Y. Z. Zhang, "Is the mitochondrial cloud the selection machinery for preferentially transmitting wild-type mtDNA between generations? Rewinding müller's ratchet efficiently," Current Genetics, vol. 56, no. 2, pp. 101-107, 2010.

[53] M. Markewitz, S. Graff, and R. J. Veenema, "Absence of RNA synthesis in shed human spermatozoa," Nature, vol. 214, no. 5086, pp. 402-403, 1967.

[54] C. Díez-Sánchez, E. Ruiz-Pesini, J. Montoya, A. Pérez-Martos, J. A. Enríquez, and M. J. López-Pérez, "Mitochondria from ejaculated human spermatozoa do not synthesize proteins," FEBS Letters, vol. 553, no. 1-2, pp. 205-208, 2003.

[55] D. Miller, P. Z. Tang, C. Skinner, and R. Lilford, "Differential RNA fingerprinting as a tool in the analysis of spermatozoal 
gene expression," Human Reproduction, vol. 9, no. 5, pp. 864869, 1994.

[56] D. Miller, D. Briggs, H. Snowden et al., "A complex population of RNAs exists in human ejaculate spermatozoa: implications for understanding molecular aspects of spermiogenesis," Gene, vol. 237, no. 2, pp. 385-392, 1999.

[57] S. M. Wykes, D. W. Visscher, and S. A. Krawetz, "Haploid transcripts persist in mature human spermatozoa," Molecular Human Reproduction, vol. 3, no. 1, pp. 15-19, 1997.

[58] I. I. Concha, U. Urzua, A. Yanez, R. Schroeder, C. Pessot, and L. O. Burzio, "U1 and U2 snRNA are localized in the sperm nucleus," Experimental Cell Research, vol. 204, no. 2, pp. 378381, 1993.

[59] A. H. Balen and H. S. Jacobs, Infertility in Practice, Churchill Livingstone, 2003.

[60] R. H. Foote, "Value of testicular and sperm profiles in optimizing reproductive success: lessons learned from selective breeding programs of domestic and laboratory animals," Progress in Clinical and Biological Research, vol. 302, pp. 107-126, 1989.

[61] K. A. Abraham and P. M. Bhargava, "Nucleic acid metabolism of mammalian spermatozoa," The Biochemical journal, vol. 86, pp. 298-307, 1963.

[62] P. M. Bhargava, "Incorporation of radioactive amino-acids in the proteins of bull spermatozoa," Nature, vol. 179, no. 4570, pp. 1120-1121, 1957.

[63] F. Martin and J. Brachet, "Autoradiographic studies on the incorporation of amino acids into spermatozoa," Experimental Cell Research, vol. 17, no. 3, pp. 399-404, 1959.

[64] J. C. White, I. Leslie, and J. N. Davidson, "Nucleic acids of bone marrow cells, with special reference to pernicious anaemia," The Journal of Pathology and Bacteriology, vol. 66, no. 1, pp. 291-306, 1953.

[65] C. M. Mauritzen, A. B. Roy, and E. Stedman, "The ribosenucleic acid content of isolated cell nuclei," Proceedings of the Royal Society B: Biological Sciences, vol. 140, no. 898, pp. 18-31, 1952.

[66] J. MacLaughlin and C. Terner, "Ribonucleic acid synthesis by spermatozoa from the rat and hamster," Biochemical Journal, vol. 133, no. 4, pp. 635-639, 1973.

[67] E. Premkumar and P. M. Bhargava, "Transcription and translation in bovine spermatozoa," Nature: New biology, vol. 240, no. 100, pp. 139-143, 1972.

[68] C. J. Betlach and R. P. Erickson, "28 s and $18 \mathrm{~s}$ ribonucleic acid from mammalian spermatozoa., Journal of Experimental Zoology, vol. 198, no. 1, pp. 49-55, 1976.

[69] N. Bissonnette, J.-P. Lévesque-Sergerie, C. Thibault, and G. Boissonneault, "Spermatozoal transcriptome profiling for bull sperm motility: a potential tool to evaluate semen quality," Reproduction, vol. 138, no. 1, pp. 65-80, 2009.

[70] S. A. Krawetz, "Paternal contribution: new insights and future challenges," Nature Reviews Genetics, vol. 6, no. 8, pp. 633-642, 2005.

[71] H. Cappallo-Obermann, W. Schulze, H. Jastrow, V. Baukloh, and A.-N. Spiess, "Highly purified spermatozoal RNA obtained by a novel method indicates an unusual $28 \mathrm{~S} / 18 \mathrm{~S}$ rRNA ratio and suggests impaired ribosome assembly," Molecular Human Reproduction, vol. 17, no. 11, pp. 669-678, 2011.

[72] T. G. Cooper, "Cytoplasmic droplets: the good, the bad or just confusing?" Human Reproduction, vol. 20, no. 1, pp. 9-11, 2005.

[73] T. G. Cooper and C.-H. Yeung, "Acquisition of volume regulatory response of sperm upon maturation in the epididymis and the role of the cytoplasmic droplet," Microscopy Research and Technique, vol. 61, no. 1, pp. 28-38, 2003.
[74] C. J. Card, E. J. Anderson, S. Zamberlan, K. E. Krieger, M. Kaproth, and B. L. Sartini, "Cryopreserved bovine spermatozoal transcript profile as revealed by high-throughput ribonucleic acid sequencing," Biology of Reproduction, vol. 88, no. 2, article 49, 2013.

[75] J. M. Feugang, N. Rodriguez-Osorio, A. Kaya et al., “Transcriptome analysis of bull spermatozoa: implications for male fertility," Reproductive BioMedicine Online, vol. 21, no. 3, pp. 312$324,2010$.

[76] I. Gilbert, N. Bissonnette, G. Boissonneault, M. Vallée, and C. Robert, "A molecular analysis of the population of mRNA in bovine spermatozoa," Reproduction, vol. 133, no. 6, pp. 10731086, 2007.

[77] C. Lalancette, C. Thibault, I. Bachand, N. Caron, and N. Bissonnette, "Transcriptome analysis of bull semen with extreme nonreturn rate: Use of suppression-subtractive hybridization to identify functional markers for fertility," Biology of Reproduction, vol. 78, no. 4, pp. 618-635, 2008.

[78] Y. Zhao, Q. Li, C. Yao et al., "Characterization and quantification of mRNA transcripts in ejaculated spermatozoa of fertile men by serial analysis of gene expression," Human Reproduction, vol. 21, no. 6, pp. 1583-1590, 2006.

[79] C. C. Yang, Y. S. Lin, C. C. Hsu, S. C. Wu, E. C. Lin, and W. T. K. Cheng, "Identification and sequencing of remnant messenger RNAs found in domestic swine (Sus scrofa) fresh ejaculated spermatozoa," Animal Reproduction Science, vol. 113, no. 1-4, pp. 143-155, 2009.

[80] P. J. Das, F. McCarthy, M. Vishnoi et al., "Stallion sperm transcriptome comprises functionally coherent coding and regulatory RNAs as revealed by microarray analysis and RNAseq," PLoS ONE, vol. 8, no. 2, Article ID e56535, 2013.

[81] G. C. Ostermeier, D. Miller, J. D. Huntriss, M. P. Diamond, and S. A. Krawetz, "Reproductive biology: delivering spermatozoan RNA to the oocyte," Nature, vol. 429, no. 6988, article 154, 2004.

[82] D. Miller, "Analysis and significance of messenger RNA in human ejaculated spermatozoa," Molecular Reproduction and Development, vol. 56, supplement 2, pp. 259-264, 2000.

[83] D. Bourc'his and O. Voinnet, "A small-RNA perspective on gametogenesis, fertilization, and early zygotic development," Science, vol. 330, no. 6004, pp. 617-622, 2010.

[84] A. E. Peaston, B. B. Knowles, and K. W. Hutchison, "Genome plasticity in the mouse oocyte and early embryo," Biochemical Society Transactions, vol. 35, part 3, pp. 618-622, 2007.

[85] T. Kono, Y. Obata, Q. Wu et al., "Birth of parthenogenetic mice that can develop to adulthood," Nature, vol. 428, no. 6985, pp. 860-864, 2004.

[86] D. Miller, M. Brinkworth, and D. Iles, "Paternal DNA packaging in spermatozoa: more than the sum of its parts? DNA, histones, protamines and epigenetics," Reproduction, vol. 139, no. 2, pp. 287-301, 2010.

[87] M. Pavone, J. Innes, J. Hirshfeld-Cytron, R. Kazer, and J. Zhang, "Comparing thaw survival, implantation and live birth rates from cryopreserved zygotes, embryos and blastocysts," Journal of Human Reproductive Sciences, vol. 4, no. 1, pp. 23-28, 2011.

[88] S. Lambard, I. Galeraud-Denis, G. Martin, R. Levy, A. Chocat, and S. Carreau, "Analysis and significance of mRNA in human ejaculated sperm from normozoospermic donors: relationship to sperm motility and capacitation," Molecular Human Reproduction, vol. 10, no. 7, pp. 535-541, 2004.

[89] R. Oliva, "Protamines and male infertility," Human Reproduction Update, vol. 12, no. 4, pp. 417-435, 2006. 
[90] C. Cho, H. Jung-Ha, W. D. Willis et al., "Protamine 2 deficiency leads to sperm DNA damage and embryo death in mice," Biology of Reproduction, vol. 69, no. 1, pp. 211-217, 2003.

[91] S. García-Herrero, N. Garrido, J. A. Martínez-Conejero, J. Remohí, A. Pellicer, and M. Meseguer, "Differential transcriptomic profile in spermatozoa achieving pregnancy or not via ICSI," Reproductive BioMedicine Online, vol. 22, no. 1, pp. 2536, 2011

[92] N. Garrido, J. A. Martínez-Conejero, J. Jauregui et al., "Microarray analysis in sperm from fertile and infertile men without basic sperm analysis abnormalities reveals a significantly different transcriptome," Fertility and Sterility, vol. 91, no. 4, pp. 1307-1310, 2009.

[93] WHO, WHO Laboratory Manual for the Examination of Human Semen and Sperm-Cervical Mucus Interaction, World Health Organisation, 1999.

[94] S. Bonache, A. Mata, M. D. Ramos, L. Bassas, and S. Larriba, "Sperm gene expression profile is related to pregnancy rate after insemination and is predictive of low fecundity in normozoospermic men," Human Reproduction, vol. 27, no. 6, pp. 15561567, 2012.

[95] A. E. Platts, D. J. Dix, H. E. Chemes et al., "Success and failure in human spermatogenesis as revealed by teratozoospermic RNAs," Human Molecular Genetics, vol. 16, no. 7, pp. 763-773, 2007.

[96] A. N. Yatsenko, A. Roy, R. Chen et al., "Non-invasive genetic diagnosis of male infertility using spermatozoal RNA: KLHL 10 mutations in oligozoospermic patients impair homodimerization," Human Molecular Genetics, vol. 15, no. 23, pp. 3411-3419, 2006.

[97] V. Grandjean, P. Gounon, N. Wagner et al., “The miR-124-Sox9 paramutation: RNA-mediated epigenetic control of embryonic and adult growth," Development, vol. 136, no. 21, pp. 3647-3655, 2009.

[98] X. Liang, D. Zhou, C. Wei et al., "MicroRNA-34c enhances murine male germ cell apoptosis through targeting ATF1," PLoS ONE, vol. 7, no. 3, Article ID e33861, 2012.

[99] C. P. Concepcion, Y.-C. Han, P. Mu et al., "Intact p53-dependent responses in miR-34-deficient mice," PLoS Genetics, vol. 8, no. 7, Article ID e1002797, 2012.

[100] M. D. Anway, A. S. Cupp, N. Uzumcu, and M. K. Skinner, "Epigenetic transgenerational actions of endocrine disruptors and male fertility," Science, vol. 308, no. 5727, pp. 1466-1469, 2005.

[101] J. Bender, "RNA-directed DNA methylation: getting a grip on mechanism," Current Biology, vol. 22, no. 10, pp. R400-R401, 2012.

[102] C. Belleannée, É. Calvo, J. Caballero, and R. Sullivan, "Epididymosomes convey different repertoires of micrornas throughout the bovine epididymis," Biology of Reproduction, vol. 89, no. 2, article 30, 2013.

[103] J. Caballero, G. Frenette, and R. Sullivan, "Post testicular sperm maturational changes in the bull: important role of the epididymosomes and prostasomes," Veterinary Medicine International, vol. 2011, Article ID 757194, 13 pages, 2011.

[104] A. Etheridge, C. P. C. Gomes, R. W. Pereira, D. Galas, and K. Wang, "The complexity, function, and applications of RNA in circulation," Frontiers in Genetics, vol. 4, article 115, 2013.

[105] A. Dean and R. M. Sharpe, "Anogenital distance or digit length ratio as measures of fetal androgen exposure: relationship to male reproductive development and its disorders," Journal of Clinical Endocrinology and Metabolism, vol. 98, no. 6, pp. 22302238, 2013.
[106] N. E. Skakkebæk, E. Rajpert-De Meyts, and K. M. Main, “Testicular dysgenesis syndrome: an increasingly common developmental disorder with environmental aspects," Human Reproduction, vol. 16, no. 5, pp. 972-978, 2001.

[107] P. M. Foster, E. Mylchreest, K. W. Gaido, and M. Sar, "Effects of phthalate esters on the developing reproductive tract of male rats," Human Reproduction Update, vol. 7, no. 3, pp. 231-235, 2001.

[108] J. R. Seckl and M. C. Holmes, "Mechanisms of disease: glucocorticoids, their placental metabolism and fetal 'programming' of adult pathophysiology," Nature Clinical Practice Endocrinology and Metabolism, vol. 3, no. 6, pp. 479-488, 2007.

[109] J. Lamarck, Philosophie zoologique ou exposition des considérations relatives à l'histoire naturelle des animaux, University of California Press, 1809.

[110] R. W. Burkhardt Jr., "Lamarck, evolution, and the inheritance of acquired characters," Genetics, vol. 194, no. 4, pp. 793-805, 2013.

[111] W. Reik, K. Davies, W. Dean, G. Kelsey, and M. Constância, "Imprinted genes and the coordination of fetal and postnatal growth in mammals," Novartis Foundation Symposium, vol. 237, pp. 19-35, 2001.

[112] P. Hajkova, S. Erhardt, N. Lane et al., "Epigenetic reprogramming in mouse primordial germ cells," Mechanisms of Development, vol. 117, no. 1-2, pp. 15-23, 2002.

[113] C. Pittoggi, L. Renzi, G. Zaccagnini et al., "A fraction of mouse sperm chromatin is organized in nucleosomal hypersensitive domains enriched in retroposon DNA," Journal of Cell Science, vol. 112, no. 20, pp. 3537-3548, 1999.

[114] M. Benchaib, V. Braun, D. Ressnikof et al., "Influence of global sperm DNA methylation on IVF results," Human Reproduction, vol. 20, no. 3, pp. 768-773, 2005.

[115] S. Houshdaran, V. K. Cortessis, K. Siegmund, A. Yang, P. W. Laird, and R. Z. Sokol, "Widespread epigenetic abnormalities suggest a broad DNA methylation erasure defect in abnormal human sperm," PLoS ONE, vol. 2, no. 12, Article ID e1289, 2007.

[116] P. N. Moreira, R. Fernández-González, D. Rizos, M. Ramirez, M. Perez-Crespo, and A. Gutiérrez-Adán, "Inadvertent transgenesis by conventional ICSI in mice," Human Reproduction, vol. 20, no. 12, pp. 3313-3317, 2005.

[117] K. Smith and C. Spadafora, "Sperm-mediated gene transfer: applications and implications," BioEssays, vol. 27, no. 5, pp. 551$562,2005$.

[118] A. Vargiolu, S. Manzini, M. De Cecco et al., "In vitro production of multigene transgenic blastocysts via sperm-mediated gene transfer allows rapid screening of constructs to be used in xenotransplantation experiments," Transplantation Proceedings, vol. 42, no. 6, pp. 2142-2145, 2010.

[119] C. Cossetti, L. Lugini, L. Astrologo, I. Saggio, S. Fais, and C. Spadafora, "Soma-to-germline transmission of RNA in mice xenografted with human tumour cells: possible transport by exosomes," PloS one, vol. 9, no. 7, Article ID e101629, 2014.

[120] K. Gapp, L. von Ziegler, R. Y. Tweedie-Cullen, and I. M. Mansuy, "Early life epigenetic programming and transmission of stressinduced traits in mammals: how and when can environmental factors influence traits and their transgenerational inheritance?" BioEssays, vol. 36, no. 5, pp. 491-502, 2014. 

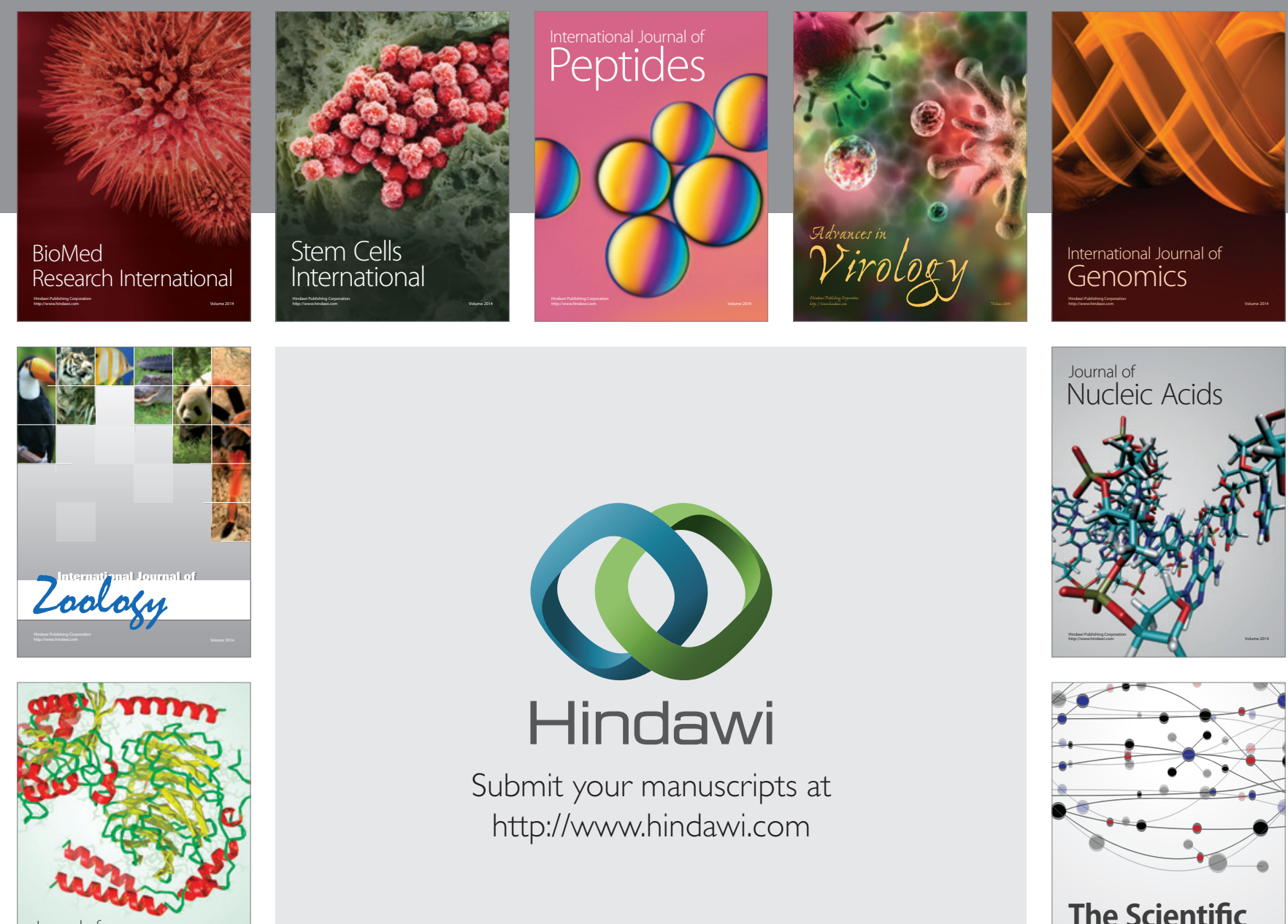

Submit your manuscripts at

http://www.hindawi.com

Journal of
Signal Transduction
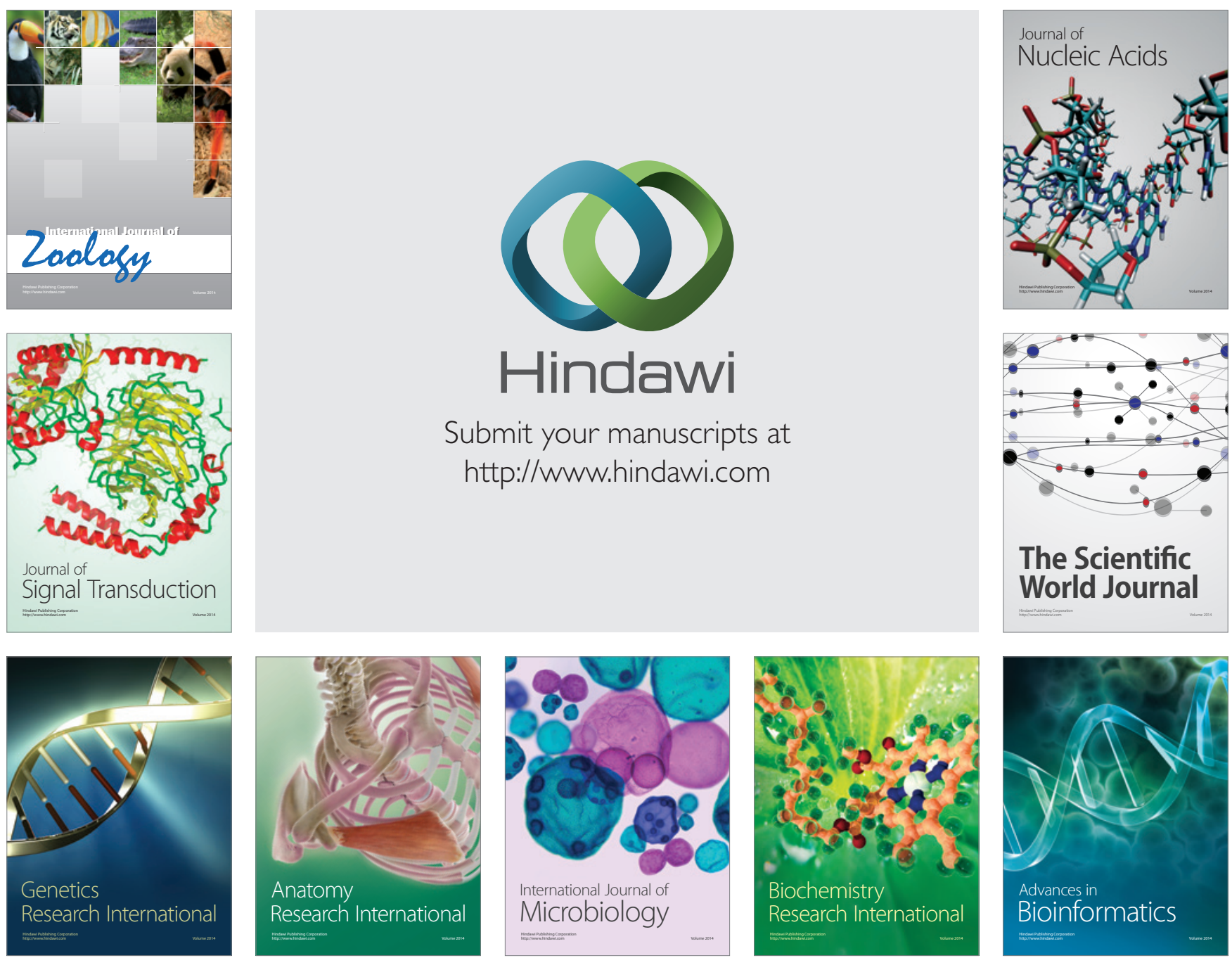

The Scientific World Journal
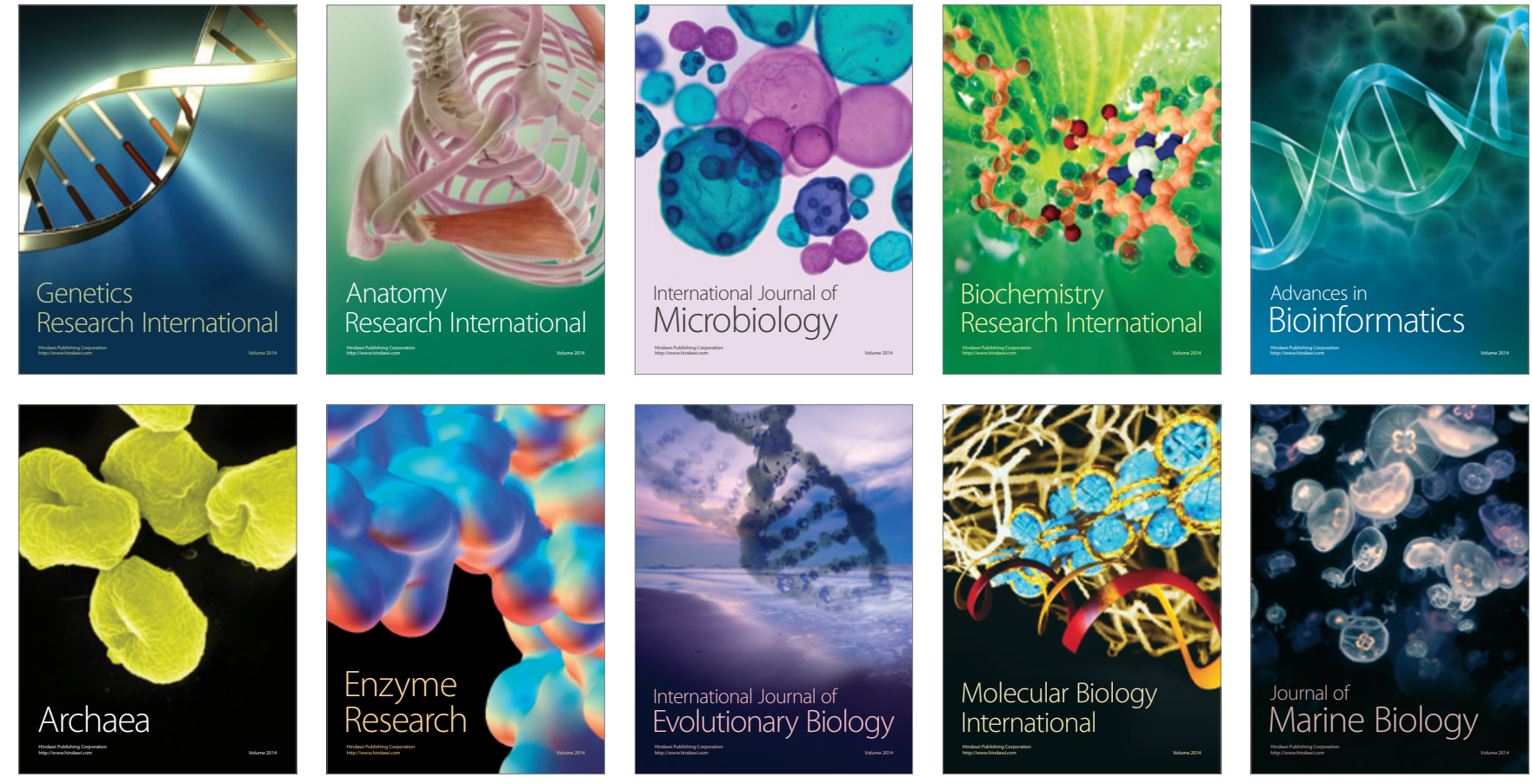